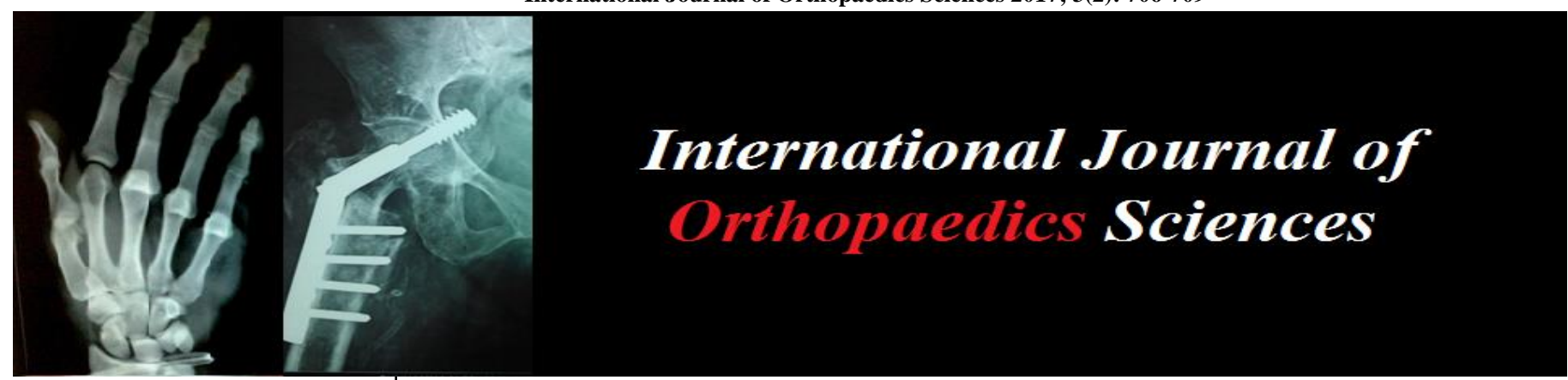

ISSN: $2395-1958$

IJOS 2017; 3(2): 706-709

(C) 2017 IJOS

www.orthopaper.com

Received: 10-04-2017

Accepted: 15-05-2017

Dr. Sanjeev Chincholi

Professor, Department of Orthopedics, Navodaya Medical

College, Raichur, Karnataka, India

Dr. Vijaya Mahanth Prasad K Assistant Professor, Department of Orthopedics, Navodaya Medical College, Raichur, Karnataka, India
Correspondence

Dr. Sanjeev Chincholi

Professor, Department of

Orthopedics, Navodaya Medical

College, Raichur, Karnataka,

India

\section{Occurrence of fracture neck femur in the elderly Indian population}

\section{Dr. Sanjeev Chincholi and Dr. Vijaya Mahanth Prasad K}

DOI: http://dx.doi.org/10.22271/ortho.2017.v3.i2h.71

\section{Abstract}

Background: The incidence of femoral neck fractures, one of the most common traumatic injuries in the elderly increases continuously due to the ageing of population on the planet and urbanization.

Aims and Objective of the Study: To study the incidence of intracapsular femoral neck fractures in the elderly population with respect to age, sex, occupation, fracture type and laterality of injury.

Materials and Methods: The prospective study included 30 patients with intracapsular femoral neck fractures referred to the Department of Orthopaedics, Ashwini Hospital, Gulbarga were selected for this study. Patients with intracapsular femoral neck fractures and aged above 55 years were considered. Patients were briefed about the nature of the study, the interventions used and written, informed consent was obtained. Further, descriptive data of the participants like name, age, sex, detailed history, were obtained by interviewing the participants and clinical examination and necessary investigations were recorded on predesigned and pretested proforma.

Results: Majority of the patients (seven patients, 23.33\%) were in the age group between 71 to 75 years and five patients, (16.67\%) each were in the age groups of 55 to 60 years, 76 to 80 years and above 80 years. In the present study, out of the 30 patients there 18 were female accounting to $60 \%$ and 12 male patients making up the remaining $40 \%$. The average interval between admission to the hospital and surgery was 3.6 days with a range of 01 to 17 days. The average duration of hospital stay was 13.3 days with a range of 7 to 26 days. The duration of hospital stay is less in our series as the patients were mobilized early. Out of 18 female patients 14 females were house wives. Three were retired from job, and one was self-employed. Among the males, seven were retired from their jobs, four males were businessman and one male patient was self-employed. Majority of the fractures occurred due to fall in bathroom (56.67\%) and fall in living room (30\%). Right side involvement was more commonly seen than the Left in this study group. Right side was involved in twenty patients making up for $66.67 \%$ of the fractures and the left was involved in ten patients accounting for $33.33 \%$ of the fractures. Out of the 30 fractures, majority were type IV fractures (23 patients) accounting for $76.7 \%$. Remaining $23.3 \%$ (07 patients) were type III fractures.

Conclusion: In conclusion, hip fractures are a serious injury in the elderly population. There is a very mortality rate and morbidity rate following hip fractures in the elderly. Once diagnosis has been made, appropriate stabilization of the patient from a medical standpoint and rapid operative fixation of the fracture or prosthetic replacement helps patients obtain a better functional result. Adequate rehabilitation in an inpatient setting, as well as at the patient's home with home health is an important adjunct to an overall successful outcome.

Keywords: Femoral neck fracture, intracapsular fractures, osteoporotic fractures, hip, epidemiology

\section{Introduction}

The incidence of femoral neck fractures, one of the most common traumatic injuries in the elderly increases continuously due to the ageing of population on the planet and urbanization. In terms of global economic instability, increasingly more funds would have to be paid by the health systems for treatment of those fractures. Probably it will be necessary to revise and optimize some current therapeutic standards ${ }^{[1]}$.

The incidence of femoral neck fractures, one of the most common traumatic injuries in elderly patients increases continuously among the ageing population on the planet ${ }^{[2,3]}$.

The UN Human Rights Commission in 1999, hasproposed to use the term "older people" instead of the word "elderly" ${ }^{[3]}$. Older people are the fastest growing age groupin the world and the annual number of hip fractures will growwith the continued ageing of population. Even if age-relatedincidence of hip fractures continues to grow with unchangedrates, the 
number of hip fractures worldwide is expected toincrease from 1.7 million in 1990 to 6.3 million in 2050. Assuming that the age-related incidence will increase byonly $1 \%$ per year, the number of hip fractures in the worldwill reach the figure of 8.2 million in $2050^{[2]}$.

Hip fractures are common and comprise about $20 \%$ of the operative workload of an orthopedic trauma unit ${ }^{[4]}$. As life expectancy is increasing all over the world Geriatric population sustaining the Fracture neck of femur are also increasing resulting in Great burden to health of society which can be better managed with Hemiarthroplasty ${ }^{[5]}$. The estimated annual cost of treating these fractures is a significant burden to any healthcare system. As a consequence, proximal femur fractures are a significant cause of morbidity and mortality in all age groups, especially in elderly ${ }^{[6]}$.

Various methods of treatment have been employed since ages. The prolonged immobilization in elderly, will further lead to decubitus problems and associated complications, and hence surgery was resorted to achieve early ambulation. It is known fact that the hip is a weight bearing joint performing many functions.

\section{Aims and Objective of the Study}

To study the incidence of intracapsular femoral neck fractures in the elderly population with respect to age, sex, occupation, fracture type and laterality of injury.

\section{Materials and Methods}

The prospective study included thirty patients with intracapsular femoral neck fractures referred to the Department of Orthopaedics, Ashwini Hospital, Gulbarga were selected for this study. Patients with intracapsular femoral neck fractures and aged above 55 years were considered. Patients below 55 years of either sex presented with femoral neck fracture associated with either acetabular or lower limb fracture or deformity of knee or ankle joint were not considered for the study. After finding the suitability as per inclusion and exclusion criteria, patients were selected for the study and briefed about the nature of the study, the interventions used and written, informed consent was obtained. Further, descriptive data of the participants like name, age, sex, detailed history, were obtained by interviewing the participants and clinical examination and necessary investigations were recorded on predesigned and pretested proforma.

\section{Results}

The present study consists of 30 cases of intracapsular fracture neck femur treated surgically by bipolar hemiarthroplasty. The study period is restricted to 18 months post operatively. Long term follow up (yearly for 5 years) could have helped further with better results. Following are the observations made.

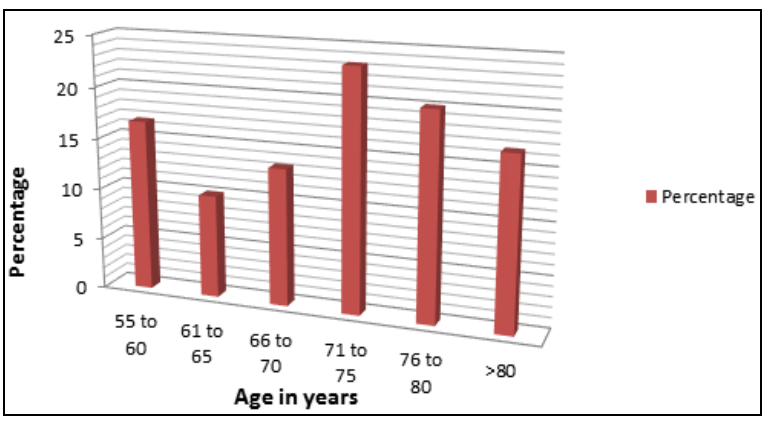

Fig 1: Age wise Distribution
Age of all the patients in this study ranged above 55 years. Majority of the patients (seven patients, 23.33\%) were in the age group between 71 to 75 years and five patients, (16.67\%) each were in the age groups of 55 to 60 years, 76 to 80 years and above 80 years.

In the present study, out of the 30 patients there 18 were female accounting to $60 \%$ and 12 male patients making up the remaining $40 \%$.

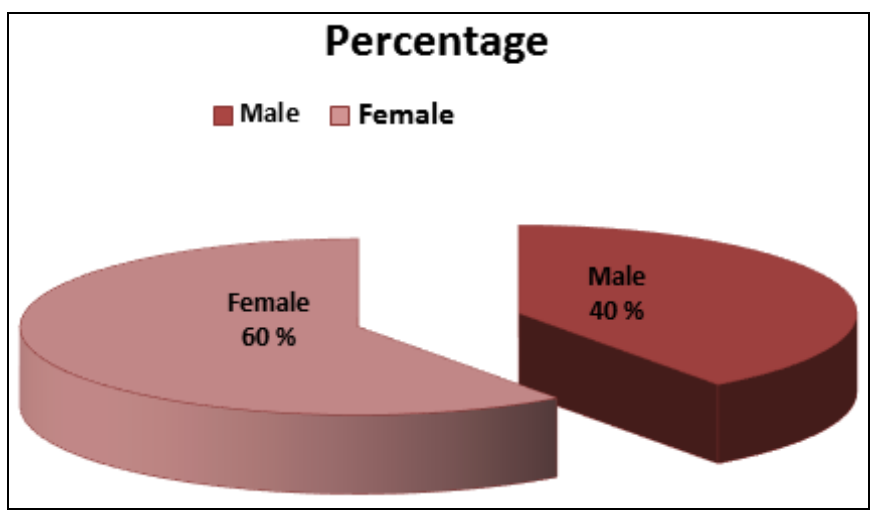

Fig 2: Gender Distribution

\section{Interval between Admission and Surgery}

The average interval between admission to the hospital and surgery was 3.6 days with a range of 01 to 17 days. (The patients were thoroughly investigated during pre-op checkup and made fit for surgery, which led to the delay in few cases).

\section{Duration of Hospital Stay}

The average duration of hospital stay was 13.3 days with a range of 7 to 26days. Except for three patients, one patient with ipsilateral distal radius fracture, one patient with circlage around prosthesis (intraoperatively periprosthetic fracture) and another patient with bed sore and electrolyte imbalance, all other patients took average time of hospital stay. The duration of hospital stay is less in our series as the patients were mobilized early.

Out of 18 female patients 14 females were house wives. Three were retired from job, and one was self-employed. Among the males, seven were retired from their jobs, four males were businessman and one male patient was self-employed.

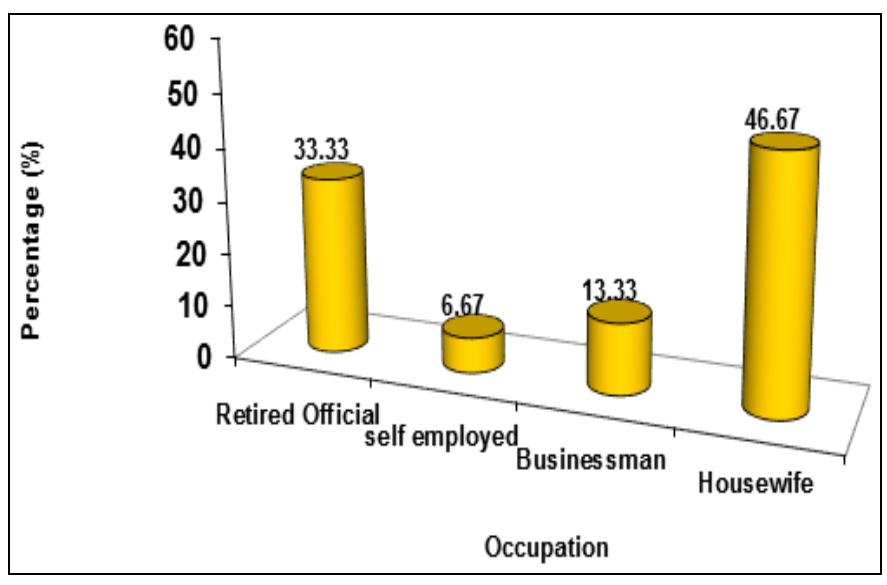

Fig 3: Occupational Distribution

Majority of the fractures occurred due to fall in bathroom $(56.67 \%)$ and fall in living room (30\%). 


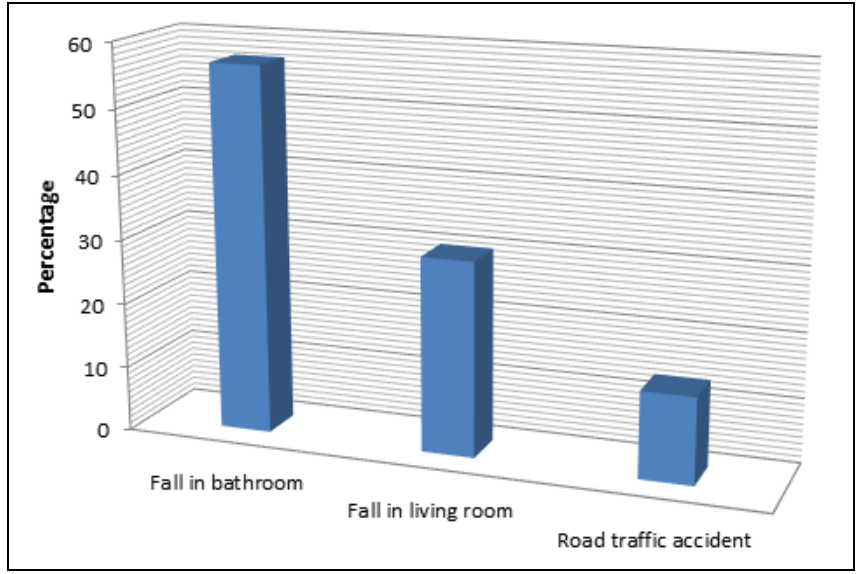

Fig 4: Nature of Trauma

Right side involvement was more commonly seen than the Left in this study group. Right side was involved in twenty patients making up for $66.67 \%$ of the fractures and the left was involved in ten patients accounting for $33.33 \%$ of the fractures.

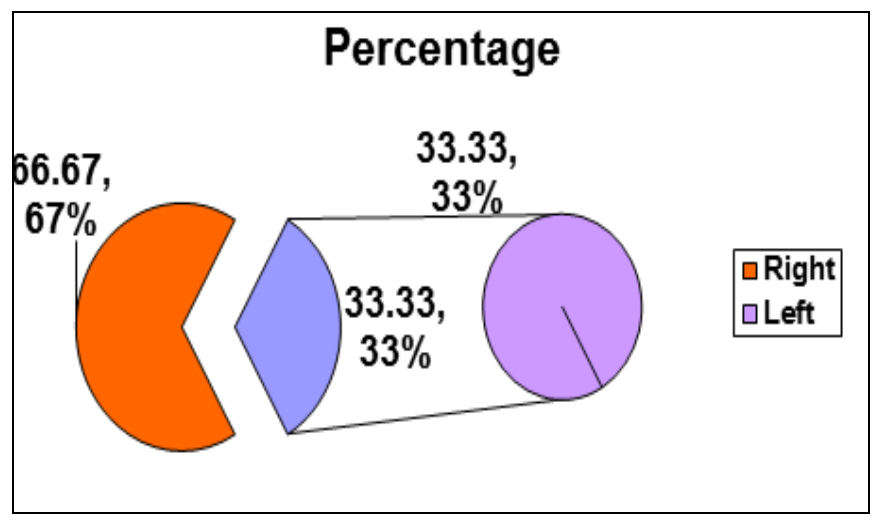

Fig 5: Injury laterality (in percentage)

Out of the 30 fractures, majority were type IV fractures (23 patients) accounting for $76.7 \%$. Remaining $23.3 \% \quad(07$ patients) were type III fractures.

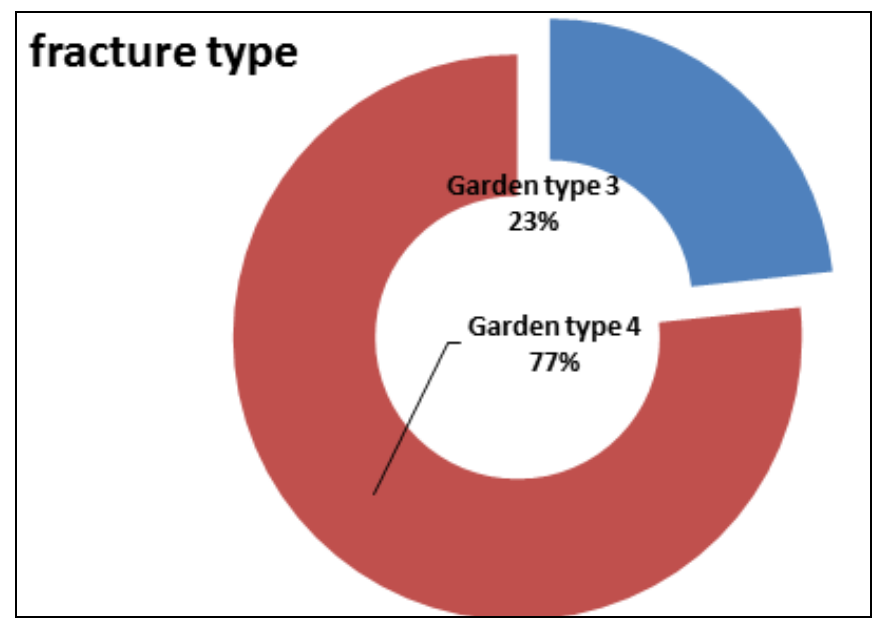

Fig 6: Fracture type (in percentage)

\section{Discussion}

Femoral neck fractures and pertrochanteric fractures are of approximately equal incidence ${ }^{[7,8]}$ and together make up over $90 \%$ of the proximal femur fractures and the remaining 5$10 \%$ are subtrochanteric. According to more recent research, half of the proximal femur fractures are intraarticular fractures of the femoral neck ${ }^{[9,10]}$. Most of the hip fractures occur after a fall. It is estimated that the lifetime risk of hip fracture was $23.3 \%$ for men and $11.2 \%$ for women ${ }^{[11]}$

The femoral neck fractures are rare among young people they are only $2 \%$ in patients under 50 years of age ${ }^{[12]}$. The incidence increases with age, and after 50 years is doubled for each subsequent decade, and is 2-3 times higher in women than in men ${ }^{[8,13]} .80 \%$ of hip fractures occur in women and $90 \%$ in people older than 50 years ${ }^{[2]}$. They are twice or three times as common for white women as for black women ${ }^{[7,8]}$. The overall annual age-standardized rates of both femoral neck fractures and trochanteric fractures are higher among white women than among black women (4.33vs. 1.91 and 4.23 vs. 1.54 per 1,000 , respectively) ${ }^{[9]}$. The increase in incidence of hip fractures with increasing the age is a result of an age-related decrease of bone mass in the proximal femur as well as of the age-related increase in the incidence of falls. The increase in incidence of hip fractures with increasing the age is a result of an age-related decrease of bone mass in the proximal femur as well as of the age-related increase in the incidence of falls.

The incidence rate in North America is the highest in the world: 201 (per 100,000 per year) in men and 511 in women [15]. The rate in Europe varies from Northern to Southern Europe, with the highest incidence in Sweden and Norway (399 per 100,000 per year in men and 920 in women) and the lowest in France and Switzerland (137 per100, 000 per year in men and 346 in women). These variations are explained by the differences in ethnic and climatic characteristics, as well as by the differences in living standards ${ }^{[14]}$.

Institutionalized geriatric patients are exposed to a higher risk of femoral neck fracture. The annual incidence in New Zealand among the elderly living in their own home is 348 per 100,000 and is 10 times higher, 3975 respectively, among those older people living in an institution or a nursing home [16].

Patients with impaired cognitive status are at increased risk of femoral neck fracture. A significant increase in the incidence was observed when comparing the population of a mental hospital with the rest of the population in Sweden. The relative hip fracture risk was seven times higher for women and 12 times higher for men with mental disorders ${ }^{[17]}$.

\section{Conclusion}

The increasingly aging population of the world will have to face the challenge of coping with the growing number of femoral neck fractures and with the increasing economic burden they represent for the healthcare system in the conditions of economic uncertainty in the future.

In conclusion, hip fractures are a serious injury in the elderly population. There is a very mortality rate and morbidity rate following hip fractures in the elderly. Once diagnosis has been made, appropriate stabilization of the patient from a medical standpoint and rapid operative fixation of the fracture or prosthetic replacement helps patients obtain a better functional result. Adequate rehabilitation in an inpatient setting, as well as at the patient's home with home health is an important adjunct to an overall successful outcome.

\section{Reference}

1. Epidemiology and social burden of the femoral neck fractures. Orlin Filipov J of IMAB. 2014; 20(4):516-18.

2. Johnell O, Kanis J. Epidemiology of osteoporotic fractures. OsteoporosInt. 2005; 16(Suppl 2):S3-7.

3. Sambrook P, Cooper C. Osteoporosis. Lancet. 2006-17; 
367(9527):2010-2018.

4. Singer BR, McLauchlan GJ, Robinson CM et al. Epidemiology of fractures in 15,000 adults: the influence of age and gender. J Bone Joint Surg (Br). 1998; 80(2):243-248

5. Dennison E, Mohamed MA, Cooper C. Epidemiology of osteoporosis. Rheum Dis Clin North Am. 2006; 32(4):617-629.

6. Serrnbo, Johnell O. Changes in bone mass and fracture type in patients with hip fractures. A comparison between the 1950s and 1980s in Malmö. Sweden. Clin Orthop Relat Res.1989; 286:139-147.

7. Allfram PA. An epidemiological study of cervical and trochanteric fractures of the femur in an urban population. Analysis of 1,664 cases with special reference to etiologic factors. Acta Orthop Scand Suppl. 1964; 65(Suppl 65):1-109. [PubMed]

8. Gallagher JC, Melton LJ, Riggs BL, Bergstrath E. Epidemiology of the fractures of the proximal femur in Rochester, Minnesota. Clin Orthop Relat Res. 1980; 150:163-71.

9. Karagas MR, Lu-Yao GL, Barrett JA, Beach ML, Baron JA. Heterogeneity of hip fracture: age, race, sex, and geographic patterns of femoral neck and trochanteric fractures among the US elderly. Am J Epidemiol. 1996; 143(7):677-682.

10. Loizou CL, Parker MJ. Avascular necrosis after internal fixation of intracapsular hip fractures; a study of the outcome for 1023 patients. Injury. 2009; 40(11):11431146.

11. Kanis JA, Johnell O, Sembo I, Sembo I, Redlund-Johnell I, Dawson A et al. Long term risk of osteoporotic fracture in Malmo. Osteoporosis Int. 2000; 11:669-674.

12. Berglund-Roden M, Swierstra Swierstra BA, Wingstrand $\mathrm{H}$, Thorngren KG. Prospective comparison of hip fracture treatment. 856 cases followed for 4 months in The Netherlands and Sweden. Acta Orthop Scand. 1994; 65(3):287-294.

13. Hedlund R, Lindgren U. Trauma type, age and gender as determinants of hip fracture. J Orthop Res. 1987; 5(2):242-246.

14. Dhanwal DK, Dennison EM, Harvey NC, Cooper C. Epidemiology of hip fracture: worldwide geographic variation. Indian J Orthop. 2011; 45(1):15-22.

15. Melton LJ 3rd, Crowson CS, O'Fallon WM. Fracture incidence in Olmsted County, Minnesota: Comparison of urban with rural rates and changes in urban rates over time. Osteoporos Int. 1999; 9:29-37.

16. Butier M, Norton R, Lee-Joe T, Cheng A, Campbell AJ. The risk of hip fracture in older people from private homes and institutions. Age Ageing. 1996; 25(5):381385.

17. Hansson LI, Ceder L, Svensson K, Thorngren KG. Incidence of fractures of the distal radius and proximal femur: comparison of patients in a mental hospital and the general population. Acta Orthop Scand. 1982; 53(5):721-726. 